\section{Sobrevivir al miedo}

AUTORES / AUTHORS

Diego Carcedo

EDITORIAL / PUBLISHING COMPANY

Madrid, Península, 2019, 272 pp.

https://www.planetadelibros.com/libro-sobrevivir-al-miedo/287561
- Recibido / Received

3 de agosto de 2020

- Aceptado / Acepted 10 de agosto de 2020

- Páginas / Pages De la 373 a la 375

- ISSN: 1885-365X

A lo largo de más de cincuenta años de ejercicio del periodismo, Diego Carcedo se ha enfrentado a situaciones límite con un peligro inminente para su vida. No se trata de unas memorias de una vida dedicada al ejercicio de la profesión sino el relato de unas experiencias únicas que nos hacen preguntarnos por el sentido de lo que hacemos, de las decisiones que tomamos, de quiénes y cómo queremos ser.

El lector se encuentra ante un libro de los que hacen amar el periodismo, el auténtico, el del reporterismo de raza, del que no para hasta encontrar la última brizna de verdad por descubrir y documentar, del que se olvida de preguntar si lo que va a indagar es peligroso solo porque está convencido de que merece la pena contarlo. Sin pretenderlo, Carcedo levanta también acta documental de una época de la televisión española (cuando en este país solo existía una televisión) en la que, contra lo que algunos podían creer, un grupo de reporteros se movían libremente por el mundo llegando donde incluso los mejores medios internacionales no llegaban. ¿Motivo? Querían ver, oír y contarlo. Los mejores tiempos de programas como Los Reporteros y los inicios de Informe Semanal dieron pie a situaciones como las que el autor narra aquí y vivió en primerísima persona.

La riqueza de estas páginas se encuentra en la mezcla de razones por las cuales el lector puede aprender mucho en ellas, aunque el autor no pretende en ningún momento dar lecciones de nada. Seguramente la razón primera por la que Carcedo decidió escribirlas fuera exorcizar los demonios interiores que se esconden en el corazón y que esperan agazapados para saltar sobre nuestro ánimo en el momento más insospechado. Lo dice el título y lo confiesa en la introducción: «Y claro que he pasado miedo: mucho, con bastante frecuencia y por muy diferentes razones» (p. 11). Espigar en la memoria algunos de esos episodios, ayuda a poner rostro a esa pasión y, al menos, tratarla de tú a tú, hablarle a la cara.

Pero además de esta primera razón, que se escapa en distintos momentos al relatar esos episodios, hay una segunda que, a mi juicio, confiere un valor añadido al libro: revisitar la memoria ayuda a desentrañar los elementos de la experiencia personal y profesional. Es ahí donde reside el particular interés para el lector que desde el ámbito de la docencia de las ciencias de la información se acerque a sus páginas. Sin pretender dar lecciones, como si de un gurú se tratara - algo en manifiesta contradicción con el modo de ser del autor- sí reco- 
pila experiencias dotadas de sentido en las que lo personal y lo profesional se dan la mano en un esfuerzo por hacer bien las cosas. $O$ al menos, lo mejor posible.

En esta breve reseña apuntaré algunos de esos elementos experienciales que ayudan a la comprensión y didáctica del periodismo, pues de algún modo tienen que ver con teoría de la información, con deontología profesional, con ética personal, con independencia y libertad... Dejo a un lado todos los demás que constituyen la parte más apasionante de los relatos de un testigo de excepción de acontecimientos de las cuatro últimas décadas del siglo xx que están en los libros de historia y que él pudo vivir en primera persona: ir en el último autobús que trataba de abandonar Saigón mientras las tropas del Vietcong se adueñaban de la ciudad, ver a los últimos españoles en abandonar el Sáhara, asistir a la guerra de Camboya, ser el único periodista extranjero que entrevistó a Idi Amín... Todos esos y más se devoran pues están relatados con la fuerza y la pasión de quien los vivió consciente de estar en momentos y acontecimientos únicos para poder contarlos. Pero ya digo que no es un libro de crónicas periodísticas, sino de experiencias vividas durante esos episodios. $Y$ ahí reside el interés de lo que destacaré a continuación y que arroja luz sobre el ejercicio del periodismo, y en particular, sobre las razones de las decisiones que se toman.

Volvemos al título y a la introducción. Hay cuatro tipos de miedos, nos dice. Y el que se pasa en las guerras, con parecer desde fuera el más lógico y alarmante, no es el principal. «Sin embargo, ese suele ser un miedo instantáneo y pasajero que la mayoría de las veces se supera, pasados unos minutos del peligro con un temblor de piernas» (p. 11). Los otros tres - señala - son el miedo a la muerte, el miedo al ridículo y

personalmente, el peor de todos ellos es el miedo a la propia conciencia, es decir, a la factura de algo que has hecho mal, pues te alterará el recuerdo, te atormentará el sueño y, por más que te empeñes, no podrás olvidarlo (p. 12).

Resulta, en consecuencia, muy interesante ir rastreando en los distintos episodios ante qué tipo de miedo nos encontramos y cuáles son las estrategias para superarlo. El primer miedo se supera con la suerte, factor inevitable también de la vida y de las peripecias que nos acontecen, como ya señalara Gandalf a Bilbo Bolsón al iniciar la aventura en El Hobbit. Lo que está en nuestra mano, pues, es comprender los modos de nuestra conciencia para afrontar las decisiones con la mayor rectitud posible. Señalo dos ejemplos de cómo está el miedo presente en las decisiones del autor y en qué nos enriquece la consideración de sus experiencias.

El primer modo en que el miedo a la propia conciencia es limitante es cuando nos dejamos confundir por los sentimientos. Los sentimientos surgen de manera espontánea. Cómo los vivimos ya es cosa nuestra. Y pueden jugarnos muy malas pasadas. Quizá sea el relato más sobrecogedor de todos los que tiene el libro. Un grupo de periodistas salía en helicóptero tras visitar a los damnificados por un grave terremoto en el corazón de los Andes peruanos. De entre los miles de supervivientes que allí estaban algunos intentaban subir al aparato. Una mujer se acerca y le pide al periodista que se lleve a su bebé para salvarlo. La escena es sobrecogedora y nos sitúa ante un dilema atroz. Ahí es donde los sentimientos pueden jugarnos una mala pasada. La razón por la que un periodista acude a un lugar así es para poder dar razón de lo que pasa y comunicarlo. No puede salvar a las decenas de miles de personas damnificadas. Pero es inevitable que la cifra y su magnitud desaparezcan ante el rostro de una madre que pide desesperada que salve a su bebé. 
Aquella crónica me costó mucho escribirla, pues en ella incluí parte de la escena. Nunca he tenido una sensación semejante. (...) Aquel sentimiento de culpa, que ni siquiera la realidad de la impotencia consigue amortiguar, aún me sigue torturando algunas noches, cuatro décadas después (p. 51).

La dificultad en este episodio está en diferenciar la impotencia de la culpabilidad. Dificultad que puede asaltarnos muchas veces a lo largo de la vida personal y profesional. Ver cómo los sentimientos nos influyen y están presentes en nuestras decisiones es una manera de intentar calibrar su peso y gestionarlos. Pueden ser motivos de nuestras acciones (para bien y para mal, ojo). Pero eso no significa que puedan ser razones para hacerlo. Ahí es donde la formación del criterio moral y deontológico nos ayuda a comprender, sopesar y decidir. Y no es fácil.

Por el contrario, nos encontramos un segundo ejemplo en el que la pasión por el trabajo bien hecho eleva lo profesional a lo personal. No se tiene un trabajo, se vive un oficio. En este sentido, el último episodio relatado es el más elocuente. El protagonista no está en un escenario conflictivo social o político. Digamos que él es la noticia. Cuando tras varios días de viajes y molestias le ve un médico, le diagnostica un infarto y el ingreso inmediato en la UCI. Estando ingresado le llaman de una agencia para que escriba la necrológica de Isidoro Álvarez, que acababa de fallecer (él no lo sabía) en el mismo hospital.

Estaba en la UCl. Me llamaron para pedírmela y, después de pensármelo un poco, me dije: “¿Y por qué no puedo hacerla?". Mejor escribir la necrológica de otro que pensar en la propia. Estaba aburrido, mirando al techo, y de pronto me sentí vivo (p. 264).

Cuando se ama la profesión como parte de la vida, los miedos claramente se matizan pues dejan de ser una pasión limitante. Hay una mucho más fuerte que nos impulsa desde el interior, que sostiene la voluntad minimizando obstáculos y potenciando la propia razón de ser y de vivir.

Me he limitado a señalar estos dos, quizá como cara y cruz del modo en que los sentimientos, las pasiones y las decisiones están entreveradas en la vida personal y profesional. Arrojar luz sobre cómo las vivimos es cosa de cada uno. En este sentido, los relatos de este libro ofrecen una aproximación muy interesante precisamente porque los muestran así, entrelazados en la experiencia desde una sincera voluntad de sentido.

Como conclusión de esta reseña me quedo con la frase que hacia la mitad del libro pone el punto final a la historia de una semana a bordo de un viejo carguero huyendo desde Vietnam a una base norteamericana en Filipinas: «las historias nunca terminan, pero a veces hasta las más duras continúan bien» (p. 202). La vida humana se compone de retazos de historia unidos en la memoria que los convierte en biografía. El miedo forma parte de ella, pero no la constituye: que continúe bien siempre depende de nuestras decisiones.

\section{Por Dr. José Ángel Agejas Esteban}

Universidad Francisco de Vitoria 